\title{
Velocity structure of the uppermost mantle beneath East Asia from $P n$ tomography and its dynamic implications
}

\author{
Suyun Wang, ${ }^{1}$ Fenglin Niu, ${ }^{2,3}$ and Guomin Zhang ${ }^{4}$ \\ Received 15 October 2012; revised 4 January 2013; accepted 7 January 2013; published 31 January 2013.
}

[1] East Asia is one of the most tectonically active regions on Earth's surface due to the collision from the India plate and the suctions induced by the subduction of the Pacific and Philippine plates. To better understand the complicated deformation and active seismicity of the area, we conducted a $P n$ traveltime tomography to estimate the compressive wave speed of the uppermost mantle beneath East Asia. We collected a total of 296,334 Pn arrivals recorded by 1354 stations from 27,777 earthquakes in a rectangular area from $60^{\circ} \mathrm{E}$ to $145^{\circ} \mathrm{E}$ in longitude, $15^{\circ} \mathrm{N}$ to $60^{\circ} \mathrm{N}$ in latitude. The data set was carefully integrated from three different catalogs after examining potential systematic biases in the catalogs. The inversion results revealed a large-scale velocity perturbation in the study area. Pn velocity in the region west to $\sim 108^{\circ} \mathrm{E}$ is approximately $10 \%$ higher than that in the east. In each region, stable blocks tend to have high $P n$ velocity while the boundary regions, which show a high level of seismicity and surface deformation, appear to have low $P n$ velocity. We further computed the Benioff strain rate in the two regions and found it correlates negatively with the averaged $P n$ velocity. Our observations here suggest that $P n$ velocity, which is predominantly determined by Moho temperature, is a good indicator of lithosphere strength.

Citation: Wang, S., F. Niu, and G. Zhang (2013), Velocity structure of the uppermost mantle beneath East Asia from Pn tomography and its dynamic implications, J. Geophys. Res. Solid Earth, 118, 290-301, doi:10.1002/jgrb.50085.

\section{Introduction}

[2] The complexity of continental deformation is well known, and it is usually attributed to the extreme heterogeneity in spatial distribution of lithospheric strength. Although many studies have been conducted to study the strength of continental lithosphere, making in situ measurement of lithospheric strength, however, is extremely difficult, if not impossible. Sonder and England [1989] found that lithospheric strength is predominantly determined by temperature within the lithosphere, especially in the mantle lithosphere, because it is believed that most of the strength of a continental plate lies in the upper crust and upper mantle [e.g., Brace and Kohlstedt, 1980; Chen and Molnar, 1983]. Generally speaking, velocity variations in the mantle are believed to be caused by changes in temperature, composition, and volatile contents. In the uppermost mantle, lateral variations in temperature are expected to be the principal cause, especially for the observed perturbations in $P$-wave velocity

\footnotetext{
${ }^{1}$ Institute of Geophysics, China Earthquake Administration, Beijing, 100081, China.

${ }^{2}$ State Key Laboratory of Petroleum Resource and Prospecting, and Unconventional Natural Gas Institute, China University of Petroleum, Beijing, China.

${ }^{3}$ Department of Earth Science, Rice University, Houston, Texas, USA.

${ }^{4}$ Institute of Earthquake Science, China Earthquake Administration, Beijing, China.

Corresponding author: F. Niu, State Key Laboratory of Petroleum Resource and Prospecting, and Unconventional Natural Gas Institute, China University of Petroleum, Beijing, 102249, China. (niu@cup.edu.cn)

(C)2013. American Geophysical Union. All Rights Reserved. 2169-9313/13/10.1002/jgrb.50085
}

[Lee, 2003]. Thus, measuring $P$-wave velocity perturbations in the uppermost mantle may provide an effective way to map lateral variations in lithospheric strength.

[3] The $P n$ phase, which is defined as the first arrival at epicentral distances from $\sim 200$ to $\sim 1500 \mathrm{~km}$, is probably the best seismic wave to measure the uppermost mantle $P$-wave velocity. The $P n$ waves dive into the mantle from the base of the crust and propagate through the high-velocity lithosphere, also known as the mantle lid, before it rises up to the surface. Because of the desirable raypaths of the Pn waves, they have been widely used in imaging the uppermost mantle velocity structure all over the globe [Hearn and $N i$, 1994; Hearn, 1996, 1999; Xu et al., 2000, 2003; Pei et al., 2002; Wang et al., 2002; Hearn et al., 2004].

[4] East Asia is one of the most tectonically active regions on Earth's surface due to the collision from the India plate and the extension induced by the subduction of the Pacific and Philippine plates (Figure 1). The western part of the area shows a compressional tectonic setting that is dominated by the collision and subsequent penetration of India into Asia [e.g., Molnar and Tapponnier, 1975]. In contrast, the eastern part of the study area is under extension during the last Mesozoic and the entire Cenozoic resulting from continuous rollback of the Pacific subduction. The wide range of surface deformations and tectonic settings provide a unique opportunity to test the hypothetic relationship between the $P n$ velocity and lithospheric strength. Various $P n$ tomography studies have been conducted in China [Ding et al., 1992; Pei et al., 2002; Wang et al., 2002; Hearn et al., 2004; Liang et al., 2004] and found an east-west contrast in $P n$ velocity that corresponds to the tectonic difference 


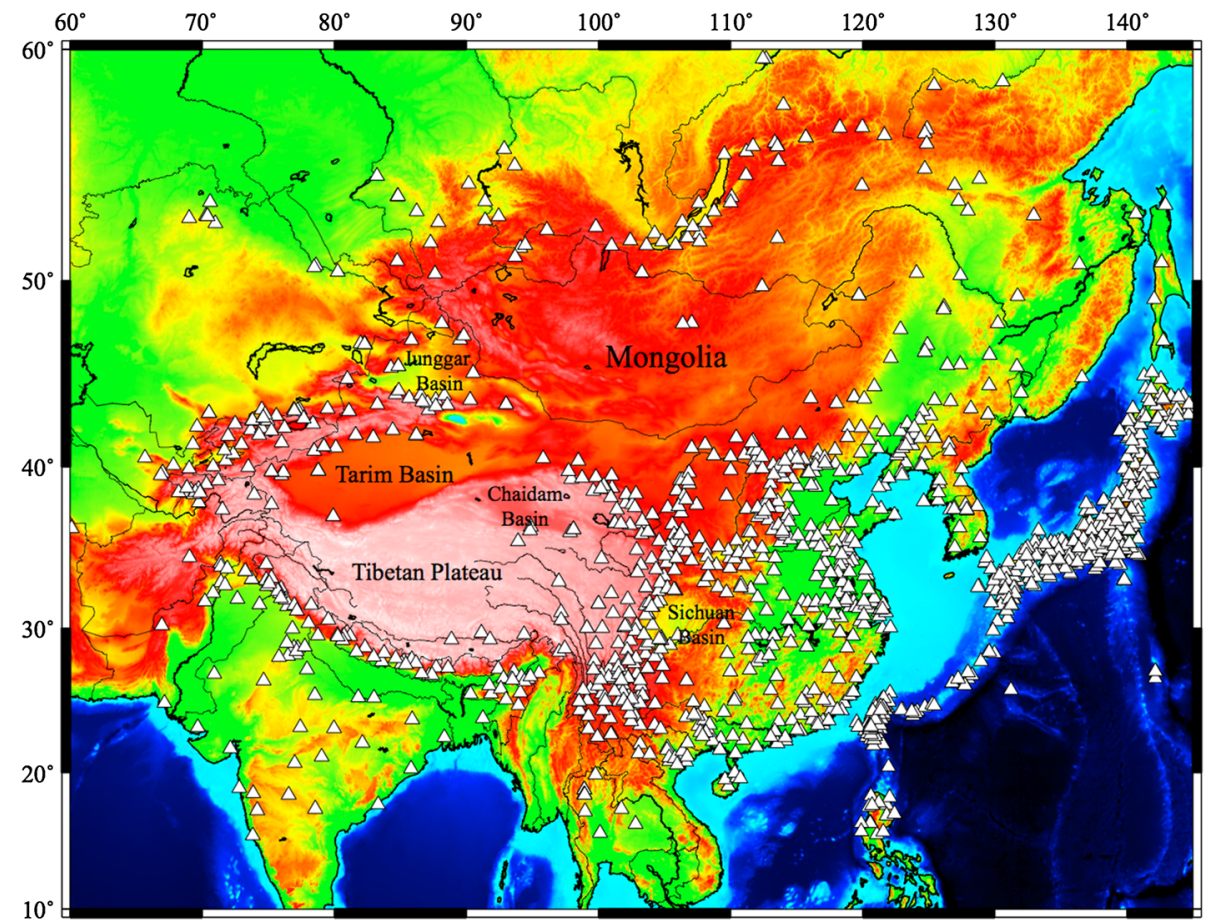

Figure 1. Map showing the topography and locations of the selected 1354 seismic stations (white triangles) of the study area.

mentioned above. In this study, we extended the study area from China to East Asia, and integrated a very large data set from three different catalogs, which allowed us to obtain a high-resolution $P n$ velocity model in the area. We then compared the velocity map with distributions of tectonic stress, lithospheric deformations and intraplate seismicity of the area. With the new velocity model and quantitative comparisons, our goal is to shed new light on the thermal structure and the associated dynamic processes beneath the area, as well as on the possible relationship between velocity structure and lithospheric strength.

\section{Data}

[5] The $P n$ data used in this study are taken from the Annual Bulletin of Chinese Earthquakes (ABCE) between 1986 and 2011, the Bulletin of the International Seismological Center (ISC) from 1964 to 2011, and the EHB Bulletin between 1960 and 1998 [Engdahl et al., 1998]. From each bulletin, we extracted $P n$ arrival times with an epicentral distance up to $9^{\circ}$ and some additional $P$-wave traveltime data in the distance range between $9^{\circ}$ and $15^{\circ}$. The bulletins have a total of approximately 485,000 arrival times in the above distance range, from which we selected the proper data for inversion.

[6] To ensure good data coverage and dense sampling of the study area, we used the following criteria to select data: (1) epicentral distance ranges from $1.8^{\circ}$ to $12^{\circ}$; (2) traveltime residuals are within -4.0 and $4.0 \mathrm{~s}$; (3) only events and stations with more than five $P n$ observations are chosen. This yielded a total of 27,777 earthquakes and 1354 stations in the study area, within $60^{\circ} \mathrm{E}-145^{\circ} \mathrm{E}$ and $15^{\circ} \mathrm{N}-60^{\circ} \mathrm{N}$. The total $P n$ raypaths are 296,334 , among which $86 \%$ are received at epicentral distance less than $9^{\circ}$. Distribution of the 1354 stations and the raypath coverage are shown in Figures 1 and 2, respectively.

\section{Method}

[7] We adopted the technique developed by Hearn [1996, 1991], which inverts $P n$ data for both velocity and seismic anisotropy. Due to the insufficient azimuthal coverage of the data around China, in this study we assumed that the velocity in the uppermost mantle is azimuthally isotropic, and only inverted for the lateral variations in the $P n$ velocity. Here we briefly reviewed the method used by Hearn [1996, 1991]. We divided the uppermost layer of the mantle into a set of two-dimensional cells, and each cell has a constant inverse velocity or slowness $\left(s_{k}\right)$ that needs to be estimated. We approximated the $P n$ traveltime residuals by the following traveltime equation:

$$
\Delta T_{i j}=a_{i}+b_{j}+\sum d_{i j k} \Delta s_{k}
$$

where $\Delta T_{i j}$ is the traveltime between the $i$-th station and the $j$-th event, $a_{i}$ and $b_{j}$ are the static delays for the $i$-th station and the $j$-th event, respectively, $d_{i j k}$ is the length of the ray segment in the mantle cell $k$ for the $P n$ wave traveling between the $i$-th station and the $j$-th event, and $\Delta s_{k}$ is the slowness perturbation of cell $k$. The unknown quantities are the station and event delays $a_{i}$ and $b_{j}$, as well as the mantle slowness perturbation $\Delta s_{k}$. The static station delay $a_{i}$ is related to the crustal thickness and velocity structure beneath the station, while the event delay $b_{j}$ ties closely to the depth of the event. If $\mathbf{x}$ is a vector formed by station delays, event delays, and slowness perturbations, then the problem can be formulated as a typical sparse linear equation system

$$
\mathbf{A x}=\mathbf{t}
$$

where $\mathbf{t}$ is a vector of traveltime residuals and $\mathbf{A}$ is a matrix corresponding to the coefficients for the delays and slowness perturbations shown in equation (1). 


\section{WANG ET AL.: EAST ASIA PN TOMOGRAPHY}

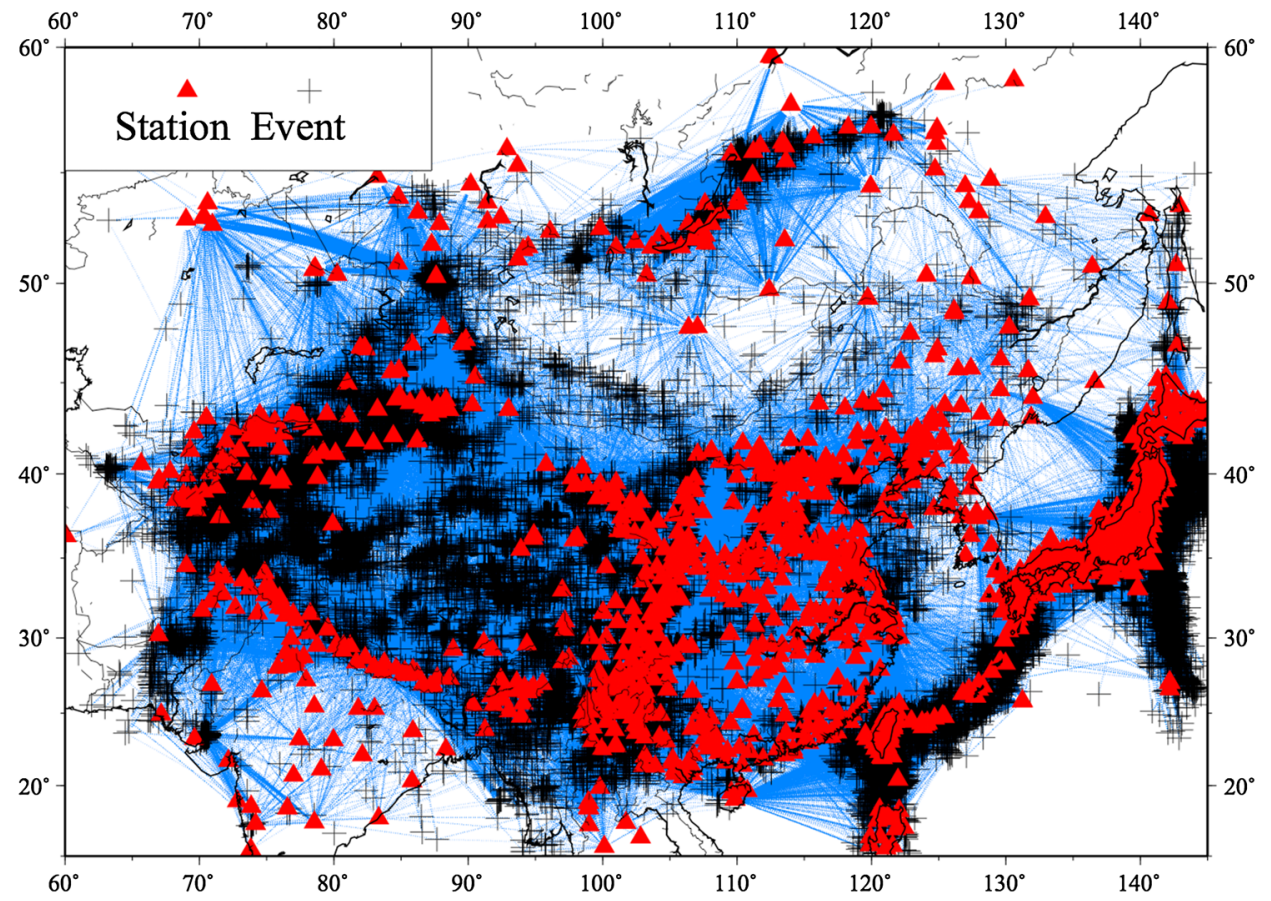

Figure 2. Map showing the locations of the earthquakes (black pluses) and stations (red triangles) and the $P n$ raypaths (blue lines). Many earthquakes occurred in the Pacific and Philippine subduction regions. The others are located mainly inside the Tibetan plateau, the Tianshan mountain ranges, and the north edge of the North China plain. Raypaths coverage inside China, Japan, and East China Sea are very good. Mongolia, eastern Siberia, and the Japan Sea have relatively low to no $P n$ coverage.

[8] To find least squares solution of equation (2), we employed a preconditioned least squares QR factorization algorithm [Paige and Saunders, 1982], which is an iterative method. We used a total of 60 iterations in our inversion. The preconditioning was incorporated to count the large variations in data coverage. No regularization was used for the station and event delays. We applied the Laplacian regularization to minimize the slowness perturbation in the study area (i.e., smooth images), and implemented the two-dimensional second-order derivative with a weighted finite difference operator. The amount of regularization is scaled by a damping coefficient, which controls the trade-off between low errors (high damping) and small resolution widths (low damping).

[9] We tested a wide range of the damping coefficient (from 500 to 1000), together with different cell size (from $0.25^{\circ} \times 0.25^{\circ}$ to $1.0^{\circ} \times 1.0^{\circ}$ ), to find the optimum values of these parameters that provide robust and high-resolution velocity structures of the study region. They are expected to provide enough variance reduction with relatively small amount of slowness perturbation. The damping coefficient and cell size used in our final inversion are 900 and $0.5^{\circ} \times 0.5^{\circ}$, respectively.

\section{Inversion Results}

[10] We first computed the average $P n$ velocity by a linear regression of the $P n$ traveltime data, which yielded an average $P n$ velocity of $8.03 \mathrm{~km} / \mathrm{s}$. The velocity perturbations were calculated with respect to this average value. We saw a gradual decrease of the misfits between the predicted and observed $P n$ traveltime during each iteration of the inversion. The rootmean-square error of the residuals was reduced from 1.58 to
$0.94 \mathrm{~s}$ after 60 iterations. The improvement in traveltime fitting occurs over all the epicentral distance range (Figure 3).

\subsection{Error and Resolution Analysis}

[11] To estimate the uncertainty in the obtained velocity perturbation, we employed a bootstrap method [Efron and Tibshirani, 1986]. The perturbation was computed from the variance of the solutions inverted from different subsets of the original $P n$ residual data. We created a total of 60 subsets of the data by randomly selecting the residual data, and conducted 60 inversions with each of the data set. Figure 4 shows the standard deviations of the velocity cells derived from the 60 inversions. Standard deviations vary from 0.0 to $0.1 \mathrm{~km} / \mathrm{s}$. Ninety-eight percent of the study area has a standard deviation less than $0.05 \mathrm{~km} / \mathrm{s}$, and $76 \%$ of the area, where dense ray coverage is available, shows an uncertainty less than $0.03 \mathrm{~km} / \mathrm{s}$.

[12] While it is an important parameter to interpret the tomographic images, the lateral resolution of the inversion is not directly given by the least squares QR factorization method. In this study, we employed the checkerboard test to estimate the apparent resolution of the inversion. We created a series of square cells with different sizes and assigned velocity perturbations that follow a sine function with amplitude of $0.3 \mathrm{~km} / \mathrm{s}$. We then generated the synthetic $P n$ traveltime data sets that share exactly the same source-receiver geometry as the real data set. We set station and event delays to zero and did not include any noise in the data. We then used the same inversion method including the damping coefficient and cell size to invert the synthetic $P n$ data sets to verify whether the inversion can reconstruct the input models. Figure 5a shows the inversion results of the $3^{\circ} \times 3^{\circ}$ checkerboard test model, indicating that 

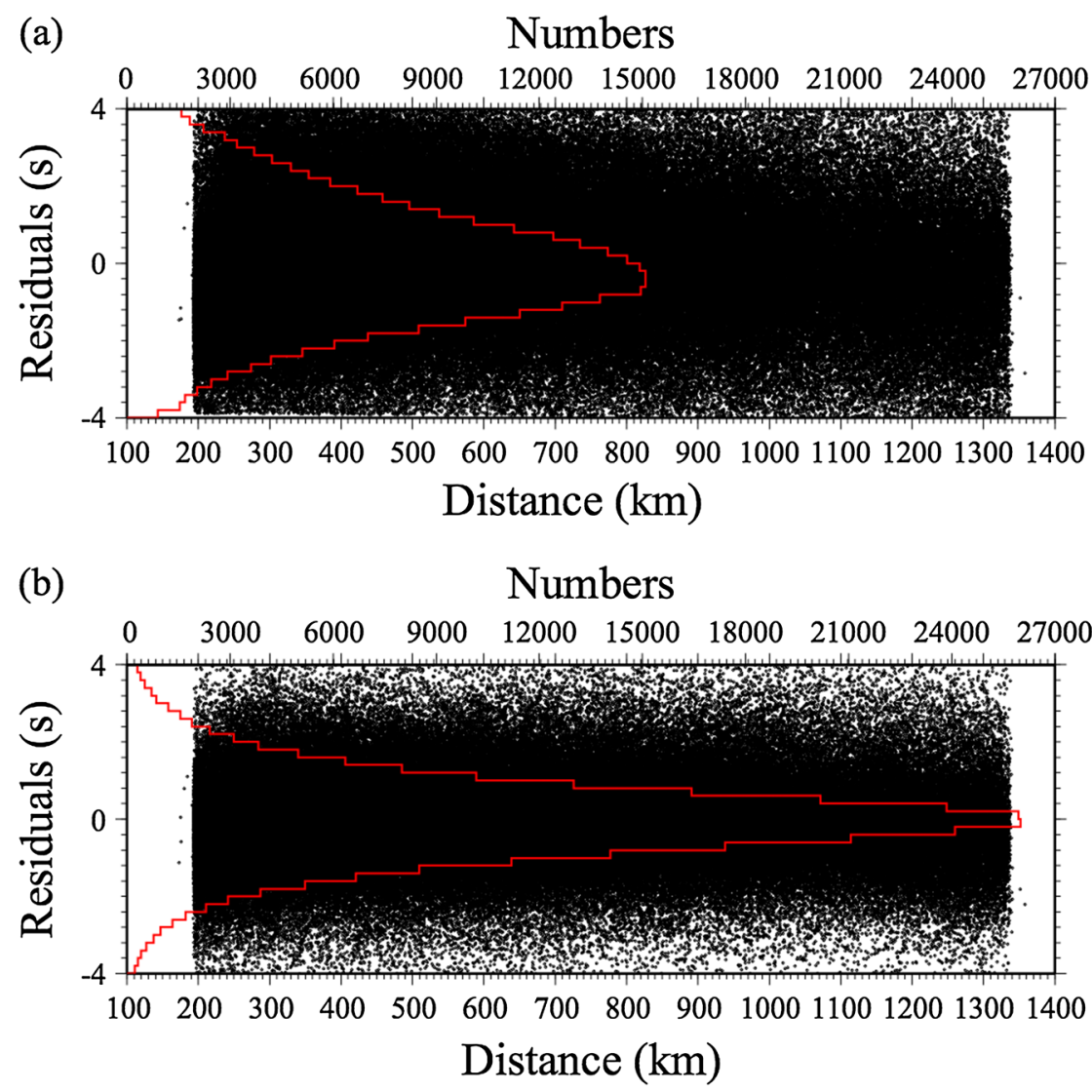

Figure 3. (a) Traveltime residuals of the first arrivals (black dots) with respect to the initial one-dimensional velocity model are shown as a function of epicentral distance (lower axis). The slightly downward curvature of the traveltimes is probably related to the small velocity increase within the lithosphere. Red curve is the histogram of the residuals, showing distribution over the -4 to 4 s range. Residuals outside this range were not selected for the inversion. (b) Same with Figure 3a except for the final traveltime residuals after the inversion.

the input structures are recovered in a large portion of the study area, which covers almost the entire China except for a small part in the northernmost Heilongjiang province. In regions with the highest raypath density, such as Japan, central China, and the Tarim basin, the resolution can reach to $2^{\circ} \times 2^{\circ}$. On the contrary, we have almost no resolution in the edges of the study area.

\subsection{Station and Event Delays}

[13] Due to operation time, noise level, and seismicity, we found that the number of $P n$ data recorded at each station is highly uneven, varying from several to several hundreds. Most of the 1354 selected stations have more than $10 P n$ records; only $13 \%$ of the stations have less than $10 P n$ arrivals. Four hundred sixty stations $(\sim 34 \%)$ show an extremely good operational record, with more than $100 P n$ traveltime data. Station delays vary from -2.20 to $2.38 \mathrm{~s}$, suggesting a large variation in crustal structure across the study area. If a station delay is caused by variation in crustal thickness, then a $1.0 \mathrm{~s}$ delay corresponds to a change of crustal thickness of $10.2 \mathrm{~km}$ assuming an averaged crustal $P$-wave velocity of $6.3 \mathrm{~km} / \mathrm{s}$ [Hearn et al., 2003]. On the other hand, a $1.0 \mathrm{~s}$ station delay corresponds to about $0.5 \mathrm{~km} / \mathrm{s}$ difference in the average crustal velocities for a $50 \mathrm{~km}$ thick crust. Li and Mooney [1998] compiled deep seismic sounding profiles across China and found that average crustal $P$-wave velocity beneath Mainland China is between
$6.2-6.5 \mathrm{~km} / \mathrm{s}$ except for deep sedimentary basins. Because the $P$-wave velocity variations are $\leq 0.3 \mathrm{~km} / \mathrm{s}$, the observed large station delays must be caused by changes in crust thickness, which have been revealed by many seismic studies [Song et al., 1993; Li and Mooney, 1998; Ma and Zhou, 2007; Chen et al., 2010; Pan and Niu, 2011; Sun et al., 2012].

[14] In principle, it is possible to further convert the station delay to crustal thickness if crustal velocity is well constrained beneath each station. In fact it is expected to better constrain Moho depth if combined with receiver function data because it can provide the averaged crustal $P$-wave velocity. However, it is beyond the scope of this study, which focuses on the velocity structure of the uppermost mantle and its dynamic implication, and we would like to leave it for future study. Here we only qualitatively discuss the lateral variations of the station delays (Figures 6). Except for those stations located in Japan and Taiwan, the delays show a clear contrast between those in the eastern and western parts of the study region. The boundary is located approximately at $108^{\circ}$ east. Stations inside the western part exhibit a positive delay with an average time of $0.33 \mathrm{~s}$. In particular, most of the stations deployed on the Tibetan plateau show a delay time of more than $1.0 \mathrm{~s}$. On the other hand stations in the eastern part, including the South China Fold System, the North China plain, northeast China, and eastern Siberia, generally possess a negative delay time. The average delay time is $-1.07 \mathrm{~s}$. We notice there are few 
WANG ET AL.: EAST ASIA PN TOMOGRAPHY

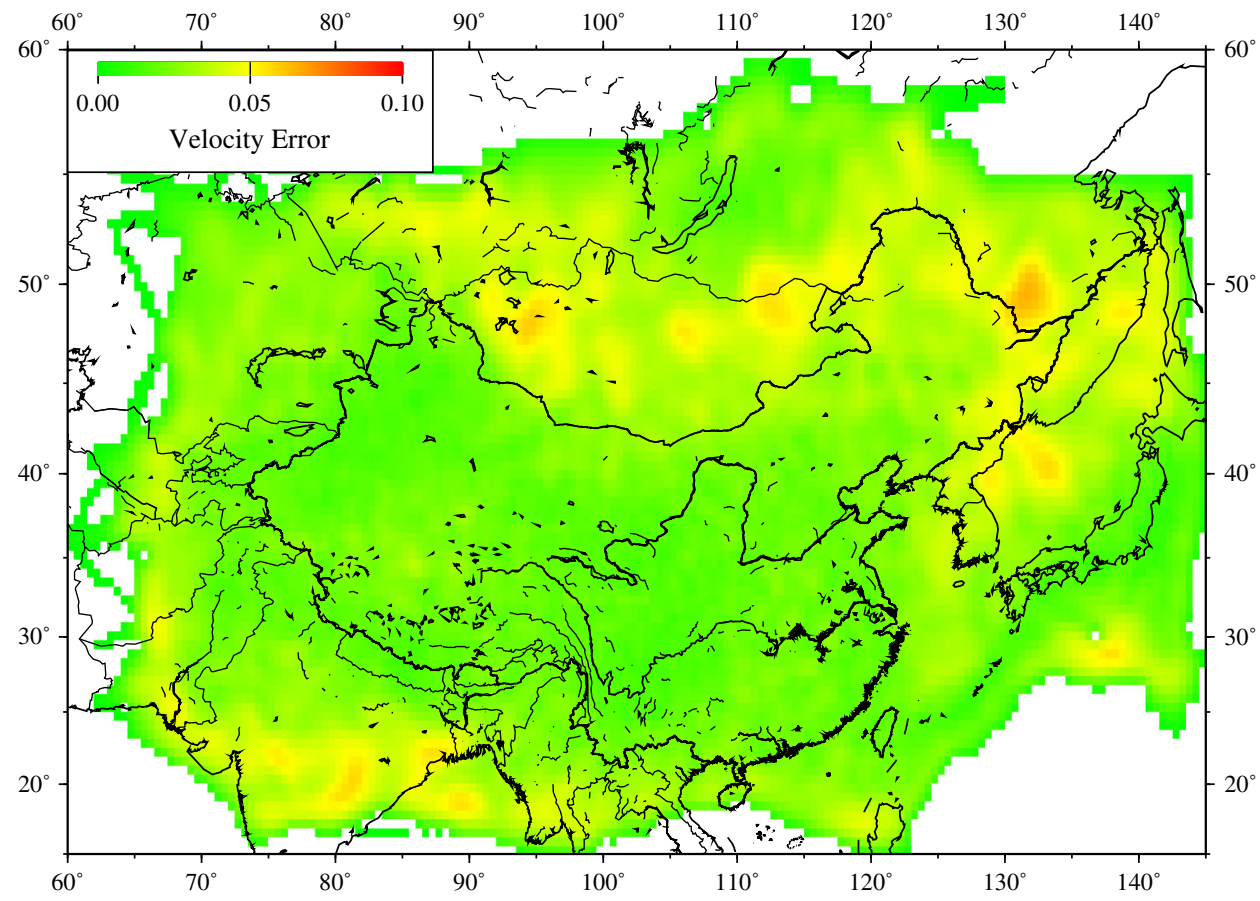

Figure 4. Map showing the standard deviation of the $P n$ velocity estimated from the bootstrap method (see text for details). In general, standard deviations are less than $0.1 \mathrm{~km} / \mathrm{s}$ for all of the study area, and are below $0.05 \mathrm{~km} / \mathrm{s}$ in regions with good raypath coverage.

stations in this region having positive station delays; these stations are generally located inside basin above a thick sedimentary layer. Stations on the arc islands, however, have a positive time delay. The distribution of station delay suggests that the western and eastern parts of the study region are underlain by a thicker and thinner than average crust, respectively. This is consistent with the east-west dichotomy in crustal thickness that is well known for this region.

[15] The inverted 27,777 event delays are shown in Figure 7, which exhibit a similar pattern as the station delays. Events west to longitude $108^{\circ} \mathrm{E}$ have positive delays with an average delay time of $0.73 \mathrm{~s}$, while those in the east show a negative delay of $-0.80 \mathrm{~s}$. We believe that this feature of the event delays also reflects the crustal thickening from east to west. In addition, earthquakes occurring beneath western Pacific subduction zones show positive delays, just like the station delays in these regions. Because both crustal structure and event depths can affect event delays, the east-west contrast shown in Figure 7 is not as clear as the one shown in Figure 6. The uncertainty in focal depth may also contribute to the large difference in delay time between adjacent events.

\subsection{Lateral Variations in the $P n$ Velocity}

[16] Figure 8 shows the velocity perturbations obtained after 60 iterations indicated by a color scale, with blue and red representing high and low $P n$ velocity, respectively. Velocity perturbations range from $\sim-0.42$ to $\sim 0.41 \mathrm{~km} / \mathrm{s}$, approximately $\pm 5 \%$ of the average velocity. Based on the amount of uncertainty, which is less than $0.05 \mathrm{~km} / \mathrm{s}$ in general, we believe that any velocity perturbations greater than $0.1 \mathrm{~km} / \mathrm{s}$ can be considered as statistically significant. Figure 8 shows a significant contrast in velocity structure at the top of the mantle between eastern and western parts of the study region bordered roughly by $108^{\circ}$ east. The eastern part has a distinctly low-velocity upper mantle compared to the western part.

[17] The $P n$ velocity map also revealed the following major structures in the western part of the study area: (1) overall the uppermost mantle has a higher velocity in this region; (2) major high-velocity regions are seen to spot around the Tibetan plateau, and show a good spatial correlation with the major basins in the area, including the Junggar and Tarim basins in the north, the Qaidam and Ordos basins in the northeast, and the Shichuan basin in the east; (3) in addition to the basins, eastern Siberia and Central Asia located at the north and west sides of the study area also possess an uppermost mantle with a high velocity; (4) the northern edge of the India plate, which is under strong collision with the Eurasia plate, also shows a high velocity, in particular beneath northern Pakistan, northern India and eastern Nepal. On the other hand, we noticed that there are also distinct low-velocity regions in this area. The major low-velocity areas are: (1) central part of the Tibetan plateau; (2) the western Sichuan and northwestern Yunnan located on the southeastern edge of the Tibetan plateau; (3) the Pamir region and the fold belt extending from Pamir at the southwest to the Lake Baikal in the northeast.

[18] The most distinct low velocity in the eastern part of the study area lies beneath the Quaternary volcanoes beneath Hokaido, NE Japan and the Izu-Bonin arc, which have been revealed by local and regional tomographic studies [Hasegawa et al., 1991; Zhao et al., 1992]. Behind the arc, we saw another low-velocity band extending from the northeast end of Taiwan, crossing the Eastern China Sea, the southwest edge of Kyushu Island, Sea of Japan, up to Sakhalin Island. The major low velocity regions are found in the central to the eastern parts of the North China craton, specifically beneath North China basin, Bohai Sea, and the Cenozoic Datong volcano located at the northern end of the Weihe-Shanxi graben system. The 
(a)

$3^{\circ} \times 3^{\circ}$ Checkerboard Resolution Test

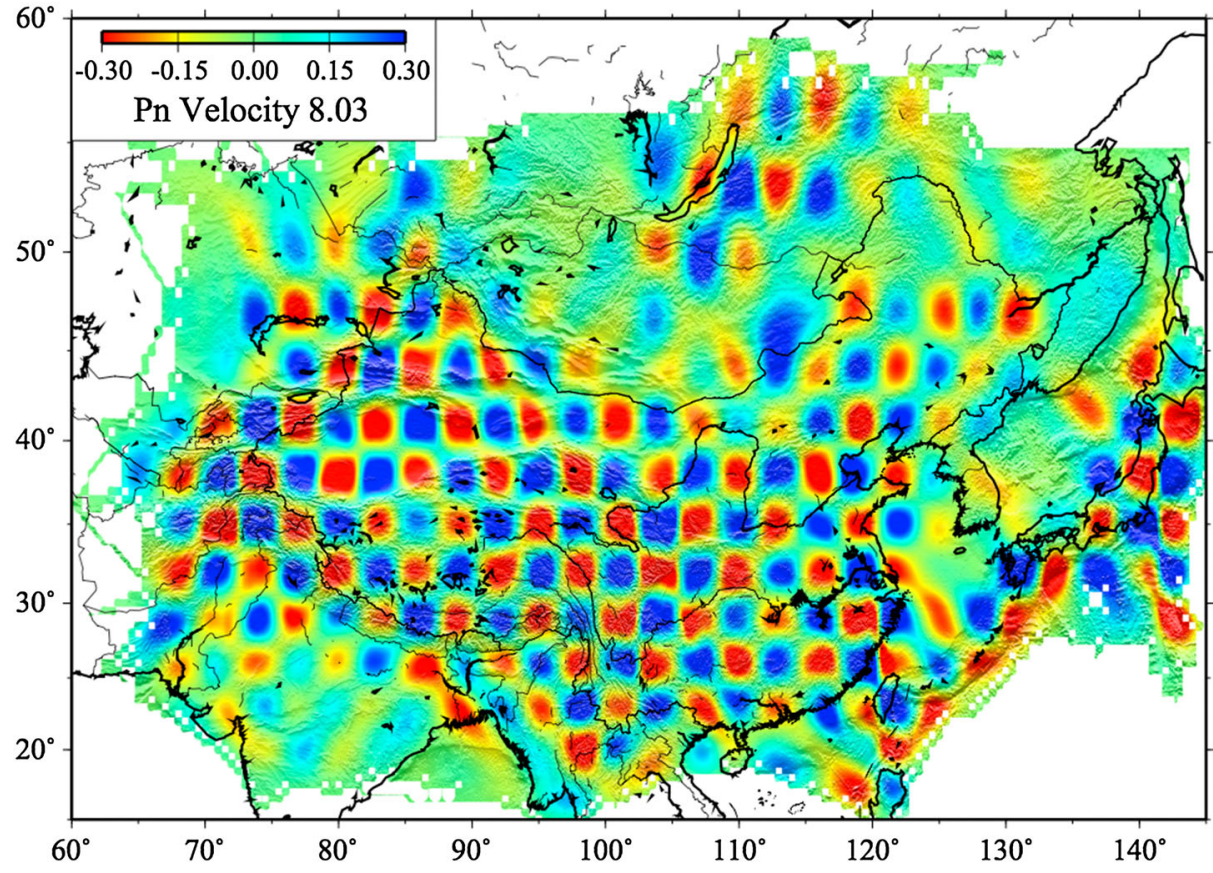

(b)

\section{$2^{\circ} \times 2^{\circ}$ Checkerboard Resolution Test}

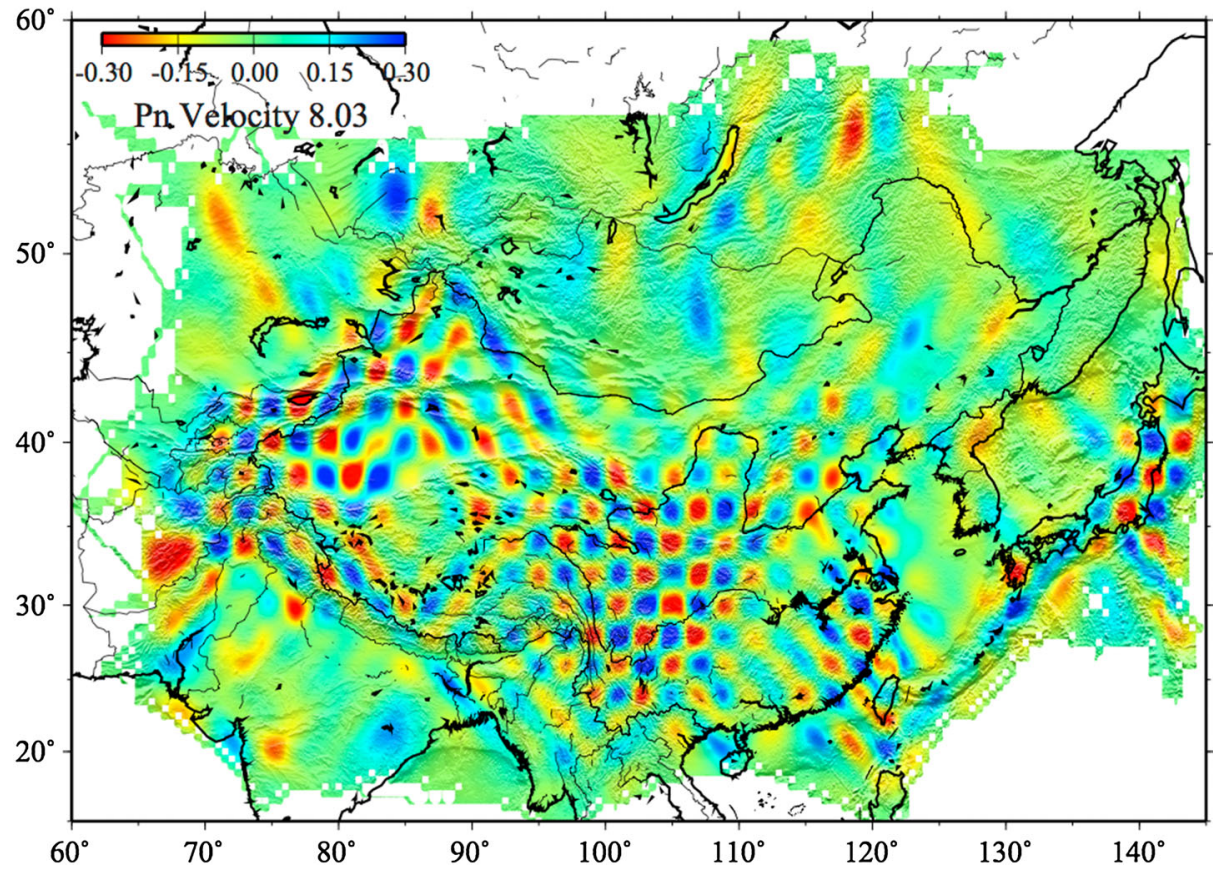

Figure 5. Results of two checkerboard-resolution tests using $3^{\circ} \times 3^{\circ}$ squares (a) and $2^{\circ} \times 2^{\circ}$ squares (b). No noise was added to the synthetic data for inversion (see text for details). In Japan, central China, western Tibet, and the Tarim Basin, where there are enough $P n$ raypath, features as small as $2^{\circ}$ can be resolved. For the rest of East Asia, resolvable features must be $3^{\circ}$ or larger in size.

south China is mixed by high and low-velocity areas. The stable Yangtze craton shows a relatively high velocity at the top of the mantle, while the low-velocity anomalies are found beneath Leizhou Pennisula, north to the Hainan Island, and its surrounding areas at the southeast edge of the South China Fold System.

\section{Discussion}

[19] Our data consist of $P n$ data from three different catalogs: $\mathrm{ABCE}$, ISC, and EHB. To investigate potential systematic biases in any individual catalog and to show the stability of our inversion results, we used each individual data set to conduct 


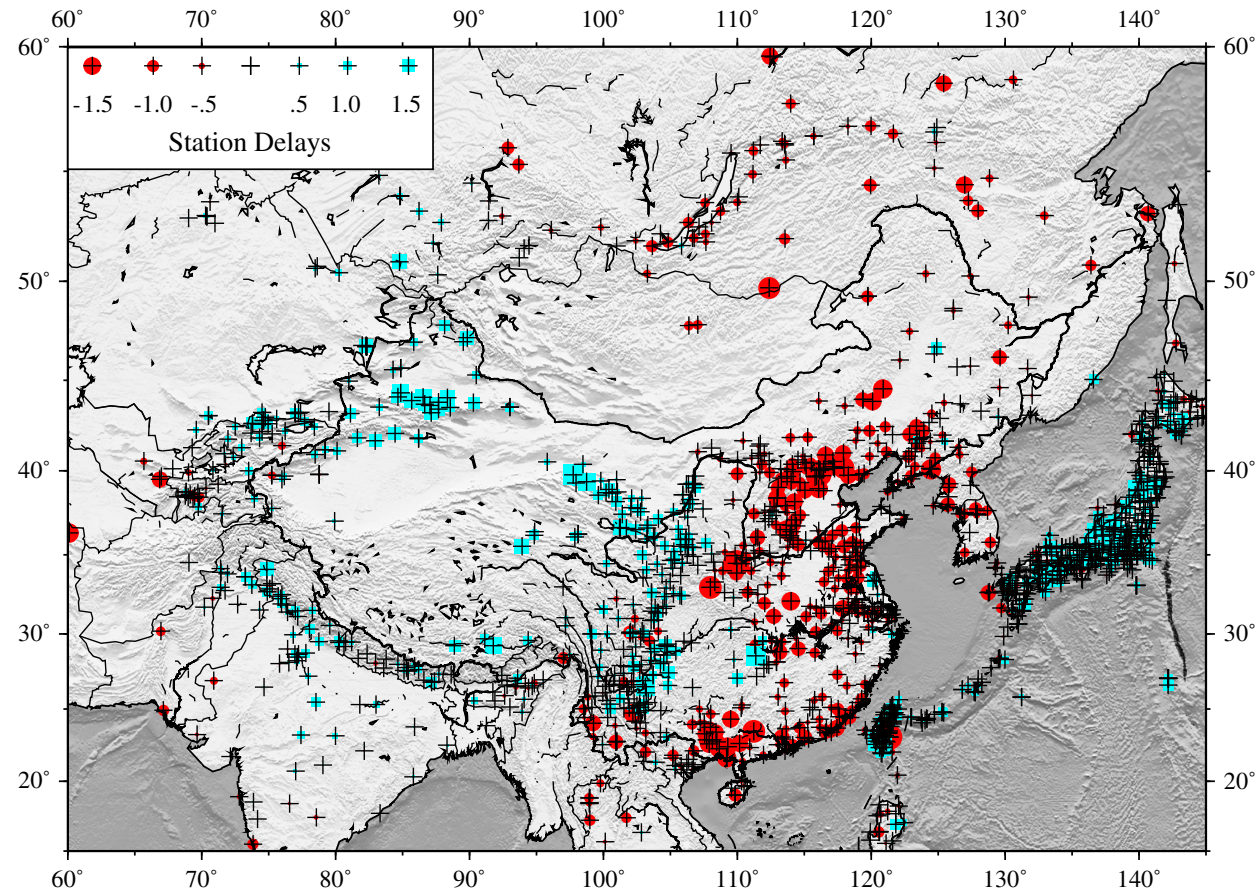

Figure 6. Distribution of station delays from the inversion. Station locations are shown by pluses. Blue squares and red circles indicate positive and negative delays, respectively, with their size proportional to the amplitude of the delays.

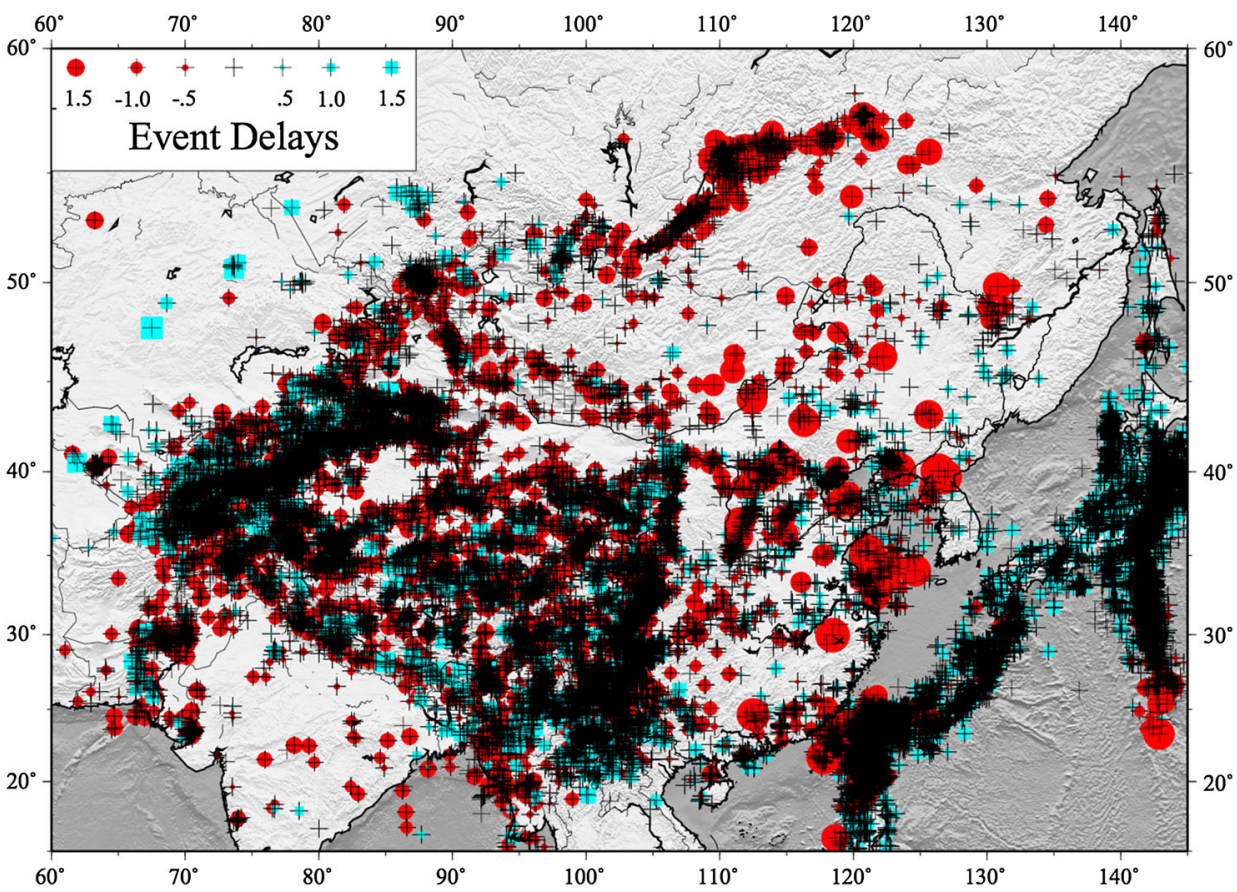

Figure 7. Distribution of event delays after the final iteration. Black crosses indicate event locations. Blue squares and red circles denote positive and negative delays, respectively, with their size proportional to delay amount.

three separate inversions. We employed the similar criterion to select $P n$ data listed in section 2. The epicentral distance was kept between $1.8^{\circ}$ and $12.0^{\circ}$ for the ABCE and ISC data, and was extended to $15.0^{\circ}$ for the EHB data, which have relatively smaller number of $P n$ arrivals. Table 1 listed the number of stations, events and raypaths of each data set, as well the resulting $P n$ velocity perturbations. For comparison, we also listed the result from the integrated data set. As shown in Table $1, P n$ velocity inverted from the EHB data set is slightly higher than the other two data sets, which is likely related to the sampling depth of 
WANG ET AL.: EAST ASIA PN TOMOGRAPHY

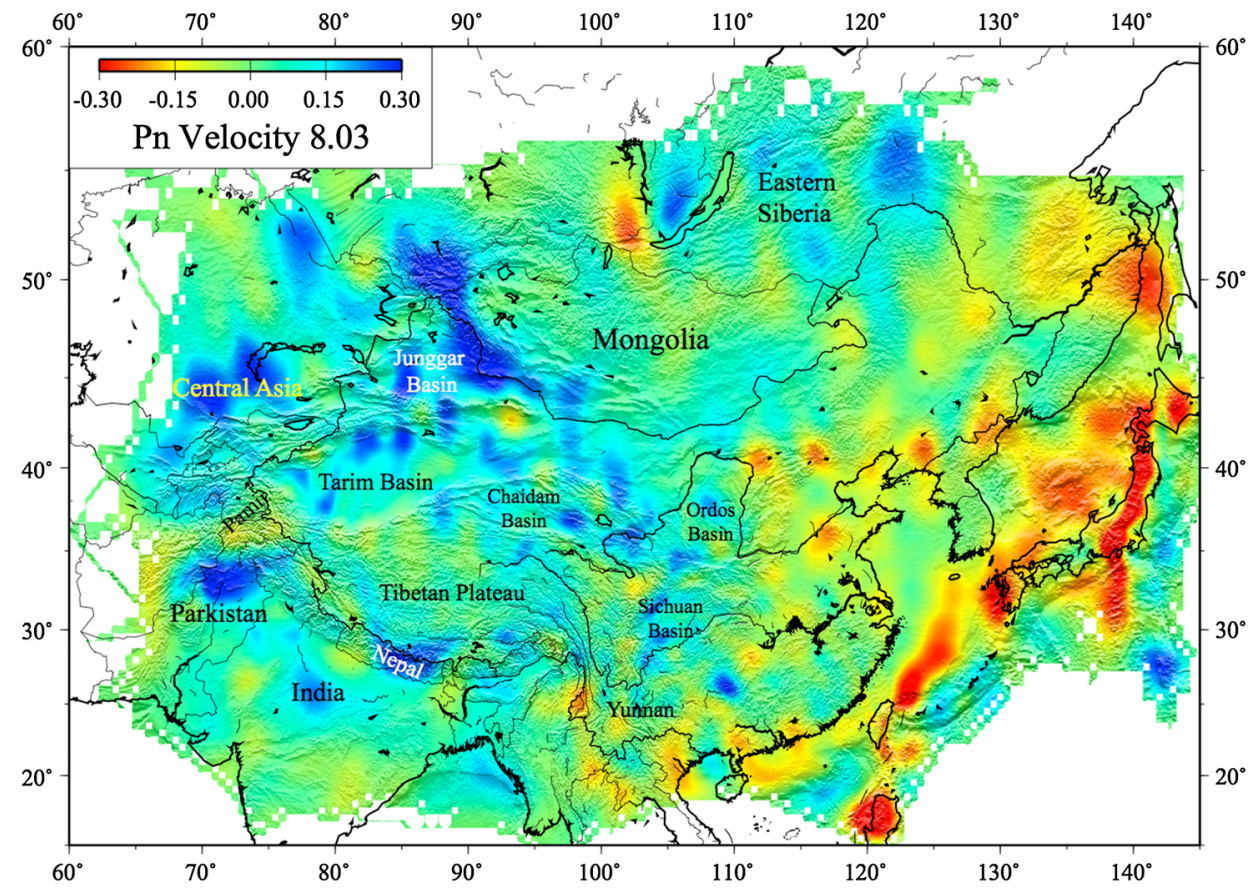

Figure 8. $P n$ velocity variations obtained from the final iteration of the inversion are plotted with superimposed topography. Perturbations deviated from the mean velocity are shown by colors, with red and blue representing the negative and positive perturbations, respectively.

Table 1. List of the Basic Information and Results of the Inversions

\begin{tabular}{|c|c|c|c|c|c|c|c|c|}
\hline \multirow{2}{*}{$\begin{array}{l}\text { Data } \\
\text { Source }\end{array}$} & \multirow{2}{*}{$\begin{array}{l}\text { Event } \\
\text { Number }\end{array}$} & \multirow{2}{*}{$\begin{array}{l}\text { Station } \\
\text { Number }\end{array}$} & \multirow{2}{*}{$\begin{array}{l}\text { Raypath } \\
\text { Number }\end{array}$} & \multicolumn{2}{|c|}{ RMS/s } & \multirow{2}{*}{$\begin{array}{c}\text { Average } P n \\
\text { Velocity }\end{array}$} & \multirow{2}{*}{$\begin{array}{c}\text { Lateral } \\
\text { Variations }\end{array}$} & \multirow{2}{*}{$\begin{array}{c}\text { Velocity } \\
(\mathrm{km} / \mathrm{s})\end{array}$} \\
\hline & & & & Before & After & & & \\
\hline $\mathrm{ABCE}$ & 14,642 & 657 & 158,704 & 1.76 & 1.08 & 8.07 & $-0.38 \sim 0.32$ & $7.69 \sim 8.39$ \\
\hline ISC & 13,037 & 771 & 137,227 & 1.30 & 0.80 & 8.01 & $-0.38 \sim 0.43$ & $7.63 \sim 8.44$ \\
\hline EHB & 694 & 250 & 7,150 & 1.68 & 0.94 & 8.14 & $-0.29 \sim 0.29$ & $7.85 \sim 8.43$ \\
\hline Integrated & 27,777 & 1354 & 296,334 & 1.58 & 0.94 & 8.03 & $-0.42 \sim 0.41$ & $7.61 \sim 8.44$ \\
\hline
\end{tabular}

$P n$ rays. As mentioned above, the $P n$ waves in the EHB data set are recorded at slightly higher epicentral distances, and are expected to travel relatively deeper into the upper mantle, as compared to the other two data sets. Therefore, the resulting $P n$ velocity, which can be considered as the averaged velocity over the mantle ray segments of the $P n$ waves, appears to be higher.

[20] $P n$ velocity maps inverted from the three individual data sets, as well as from the integrated data set are shown in Figure 9. Because the ABCE data set covers only the mainland China, the resolvable area is thus limited inside China and the back arc basins east to China (Figure 9a). The ISC data set, on the other hand, covers a much broader area, and shows good imaging power to the regions surrounding China (Figure 9b). The achievable resolution of certain parts of China, such as the northeast China, however, is much more reduced than that of the ABCE data (Figure 9b). We also noticed that the large velocity perturbations, such as the velocity contrast between eastern and western China, are clearly shown on both of the ABCE and ISC maps, although there are many differences in smallscale structures. The EHB data essentially show a similar area coverage as the ISC data, but with a lower raypath density (Figure 9c). The $P n$ velocity images from the three individual data sets are rather consistent with each other, suggesting that there are no systematic biases in any of them, and that they can be integrated into one data set to obtain better coverage and therefore to improve the lateral resolution of the tomographic image (Figure 9d). The consistence between different inversions suggests that the results with the integrated data set are robust. Our results here are generally consistent with those of the previous studies [Hearn et al., 2004; Liang et al., 2004; Pei et al., 2007]. The major features described in the last section, such as, a distinctly high $P n$ velocity in the major basins in western China and a very low $P n$ velocity in the North China plain. In the following paragraphs, we compare the $P n$ velocity structure obtained here with tectonics, stress and seismicity in the region to understand its geodynamic implications.

[21] Sonder and England [1989] suggested that the Pn velocity in the uppermost mantle may be related to the orientation and magnitude of stress in the lithosphere. Regions with compressive stress setting tend to show high $P n$ velocity, while those under horizontally extensional setting often exhibit a low $P n$ velocity. The present-day tectonic setting of East Asia is featured by an Indian-Eurasian collision in the west and a Pacific subduction in the east. The prolonged collision between India and Eurasia created a nearly north-south convergence in the western part of the study region, and shaped it into plateaus and highlands with elevations of $\sim 500-6000 \mathrm{~m}$ above sea level. On the other hand, the rollback of the Pacific slab 

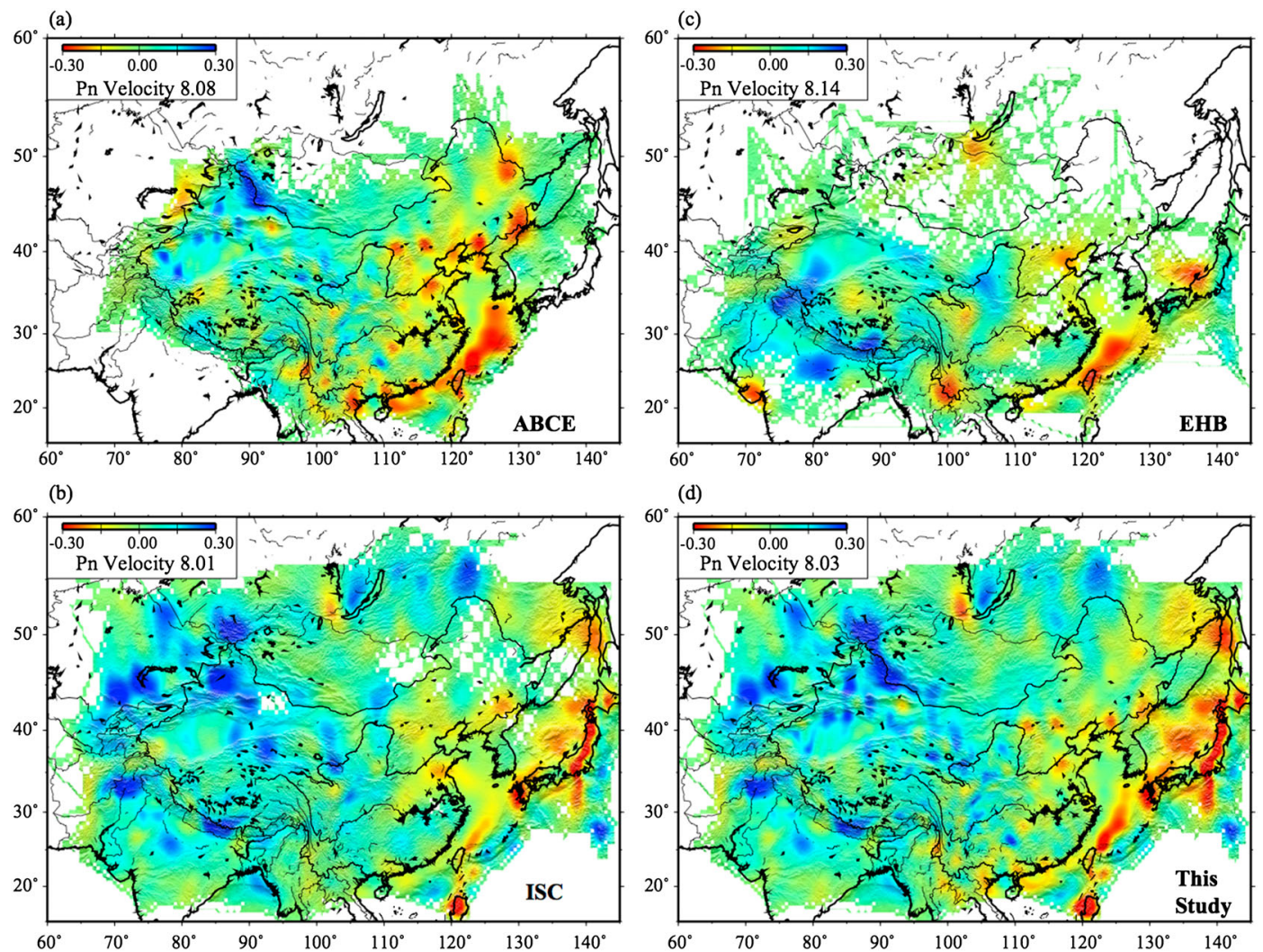

Figure 9. Results from inversions with the (a) ABCE, (b) ISC, (c) EHB catalogs, and (d) the integrated data set of the three catalogs. The ABCE data set compiled by the China Earthquake Administration has excellent coverage inside China, but has almost no resolution in the surrounding areas. The ISC and EHB data sets, on the other hand, cover a much broader area. The complementary feature of the three data sets is well illustrated in the joint inversion shown in Figure 9d, which shows a good resolution in almost the entire East Asia.

appeared to play a dominant role in shaping the eastern part of the study area, which is comprised primarily of extensional basins with an altitude less than $200 \mathrm{~m}$. The observed high $P n$ velocity in the west and low $P n$ velocity in the east thus may reflect the predominantly compressional and extensional tectonics of the two regions, respectively.

[22] To further quantify the difference in stress field between the western and eastern regions that may lead to the observed $P n$ velocity contrast, we compiled the horizontal $P$-axis orientation data from the global CMT catalog [Dziewonski et al., 1981] covering the period between January 1976 and August 2011. We chose thrust and strike-slip earthquakes that have the maximum compressional stress lying in the horizontal direction. A total of 2548 earthquakes, which include 845 strike-slip events and 1703 thrust events, were selected inside the study region. The orientation of the $P$-axis is shown in Figure 10 and is listed in Table 2. In Figure 11, we showed the orientation as a function of the longitude of the epicenter. We divided the study area into eight $10^{\circ}$ wide longitudinal bands and analyzed the distribution of the $P$-axis azimuth with earthquakes occurring in each band. Because the orientation of the $P$ axis has a twofold rotational symmetry, we only considered azimuthal range between $0^{\circ}$ to $180^{\circ}$. We divided them into four azimuthal ranges: $0^{\circ}-45^{\circ}, 46^{\circ}-90^{\circ}, 91^{\circ}-135^{\circ}$, and $136^{\circ}-180^{\circ}$, and for each azimuthal bin, we counted the number of earthquakes whose $P$-axis azimuth fall into the bin. The counting was

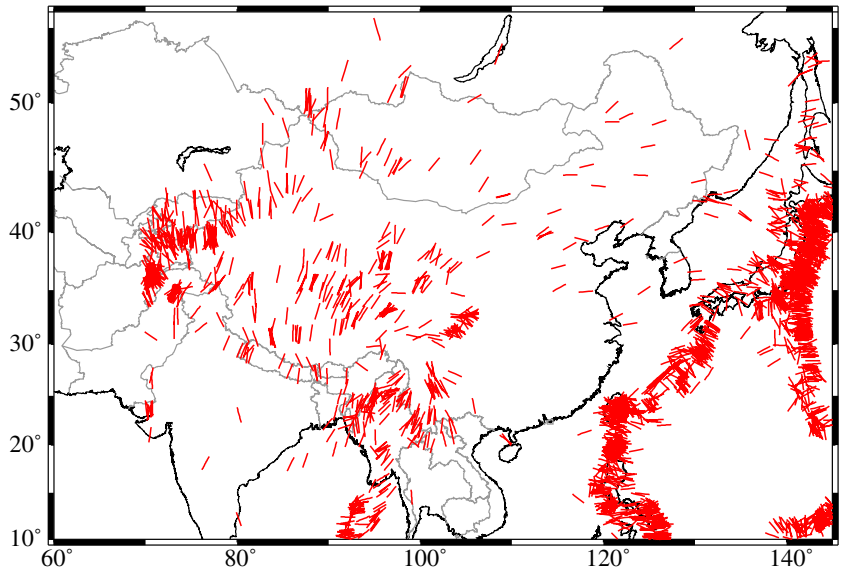

Figure 10. Orientation of the $P$ axis is plotted at the location of each earthquake. The focal mechanisms are selected from the global CMT catalog for earthquakes occurring between 1 January 1976 and 31 August 2011.

performed for all the eight longitudinal bands and the numbers are shown in Table 2. We grouped the eight longitudinal bands into the eastern and western regions. For each region, we also computed the percentage of earthquakes in the four azimuthal ranges to see the dominant orientation of the stress field. We 
Table 2. Number of Earthquakes and $P$-axis Distribution

\begin{tabular}{|c|c|c|c|c|c|c|c|c|c|c|}
\hline \multirow{2}{*}{$\begin{array}{l}P \quad \text { Axis } \\
\text { Orientation }\end{array}$} & \multicolumn{5}{|c|}{ Western Region } & \multicolumn{5}{|c|}{ Eastern Region } \\
\hline & $70-80^{\circ}$ & $81-90^{\circ}$ & $91-100^{\circ}$ & $101-110^{\circ}$ & $\%$ & $111-120^{\circ}$ & $121-130^{\circ}$ & $131-140^{\circ}$ & $141-145^{\circ}$ & $\%$ \\
\hline $0-45$ & 105 & 62 & 152 & 23 & 43.1 & 4 & 23 & 15 & 35 & 4.4 \\
\hline $46-90$ & 25 & 4 & 92 & 25 & 18.4 & 24 & 205 & 30 & 144 & 23.0 \\
\hline $91-135$ & 29 & 0 & 19 & 24 & 9.1 & 22 & 289 & 161 & 560 & 58.8 \\
\hline $135-180$ & 145 & 41 & 16 & 31 & 29.4 & 1 & 70 & 55 & 117 & 13.8 \\
\hline
\end{tabular}

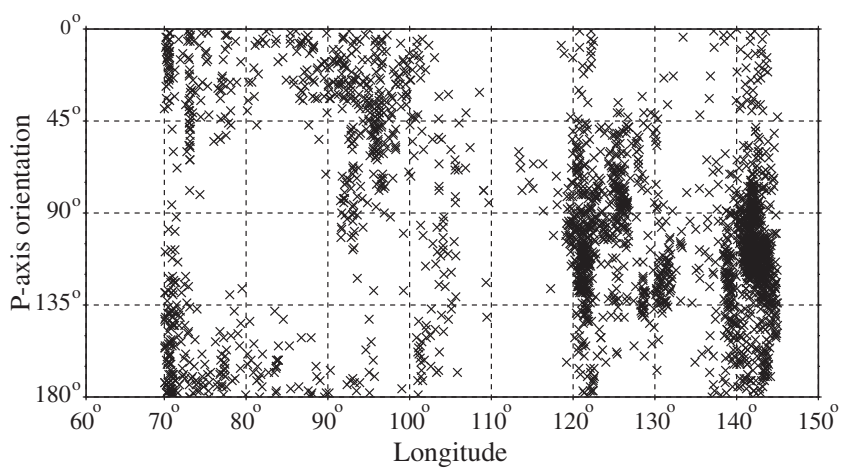

Figure 11. Orientation azimuth of the $P$ axis is shown as a function of epicentral longitude. Note the significant contrast between the west and east (divided by longitude $110^{\circ} \mathrm{E}$ ), which show a predominantly NS and EW compressional directions, respectively.

further approximated the first $\left(0^{\circ}-45^{\circ}\right)$ and fourth azimuthal ranges $\left(136^{\circ}-180^{\circ}\right)$ as the NS direction and the other two ranges as the EW direction. For the western region, $\sim 74 \%$ of the 940 earthquakes have a $P$ axis oriented along the NS direction, while $81 \%$ of the earthquakes in the eastern part show an EW-oriented $P$ axis, suggesting that there is indeed a significant difference in principal stress direction between the western and eastern regions. The amplitude of the stress is difficult to estimate from either geodetic and seismic data especially at seismogenic depth. Thus, we only use the orientation of $P$ axis here to argue the fundamental difference in the stress field between the two regions. We speculate that this stress difference might have, either directly or indirectly, led to the development of the observed east-west velocity dichotomy in the $P n$ velocity structure.

[23] As shown above, the observed $P n$ velocity structure may be somehow related to the tectonic stress in the study area. Because $P n$ velocity reflects the elastic properties of the uppermost mantle, it thus may have a certain correlation with lithospheric strength, which is believed to control continental deformation and seismicity. Because of the strong interaction between the Indian, Eurasia, Pacific, and Philippine plates, East Asia is one of the most tectonically active regions on the Earth, with a very high level of seismicity. Many geodetic studies of this area indicated that the deformations are extremely heterogeneous, and are best described as relative motions among elastic blocks bounded by weak faults [Thatcher, 1995]. The block or microplate model is an analogy to global tectonics, with blocks being much smaller, typically $\sim 100-1000 \mathrm{~km}$ in size. Using geodetic, geologic, and seismic data, Zhang et al. [2003, 2004] divided east Asia into six major blocks, the Northwest block, Tibetan block, Yunnan-Burma block, South China block, North China block, and Northeast Asia block, as shown in Figure 12.

[24] In Figure 12, we also plotted the epicenters of strong earthquakes with a magnitude $\geq 6$ occurring between January 1900 and March 2012. Locations of the epicenters were taken from the catalog published by the ISC. We found a total of $3016 \mathrm{M6}+$ earthquakes in the study region, which consists of 2223 shallow, 540 intermediate-depth, and 253 deep events, respectively. As shown in Figure 12, most of the strong intraplate earthquakes occurred at or near the block boundaries, which usually exhibit a lower $P n$ wave velocity compared to the surrounding blocks.

[25] To further quantify the correlation between $P n$ velocity structure and seismic activity, we computed the average $P n$ velocity $\left(\overline{V_{\mathrm{Pn}}}\right)$ beneath each block, as well as the Benioff strain rate [Benioff, 1951] of the block,

$$
e=\frac{\sum_{i=1}^{N} \sqrt{E_{i}}}{T S}
$$

here $E_{i}$ is the elastic energy released by the $i^{\text {th }}$ earthquake, and $N$ is the total number of earthquakes occurring in each of the blocks during the period $T$, and $S$ is the total area of the block. According to Benioff [1951], the square root of the radiated

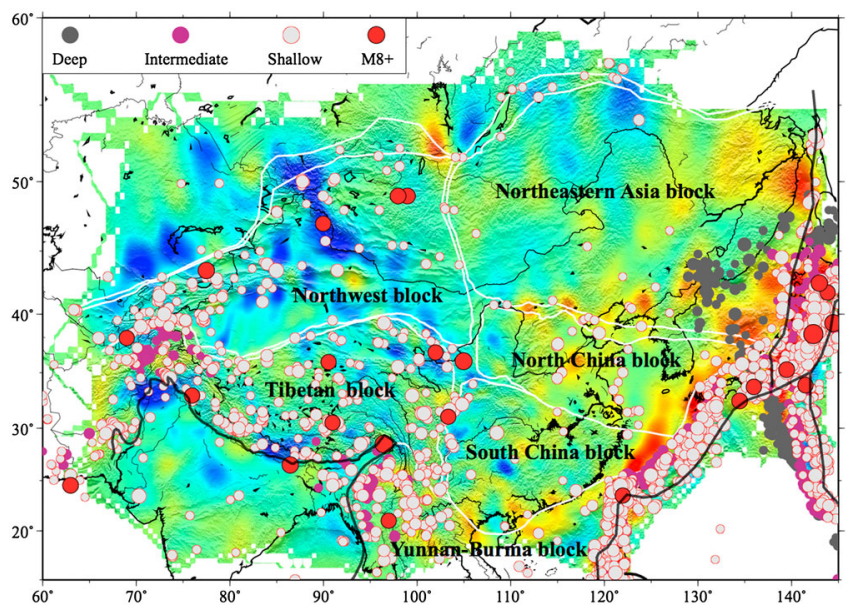

Figure 12. Distribution of strong earthquakes is shown together with major tectonic blocks in the study area. Thick black lines indicate plate boundaries of the HS3-NUVEL-1A model [Gripp and Gordon, 2002]. White lines are boundaries of tectonic blocks [Zhang et al., 2003]. Gray, purple, and while dots, respectively, represent deep, intermediate, and shallow earthquakes with a moment magnitude between 6.0 and 7.9. Red circles indicate shallow earthquakes with a magnitude equal or greater than 8.0. 
energy of an earthquake is proportional to the elastic strain preceding the earthquake. Because the moment magnitude was not determined for most of the earthquakes occurring in the early days, we thus have employed Gutenberg's empirical energy-magnitude relation $\log E=1.5 M+4.8$ [Gutenberg and Richter, 1956] to make a rough estimate of the elastic energy release. Here the unit of elastic energy is Joule. The calculated average $P n$ velocity and the Benioff strain rate are listed in Table 3. The calculated Benioff strain rates of the three western blocks are approximately an order of magnitude larger than those of the three eastern blocks. When the entire study region is considered, there seems no obvious correlation between the

Table 3. Average $P n$ Velocity and Strain Energy Release Rate

\begin{tabular}{llcc}
\hline \multirow{2}{*}{ Region } & \multicolumn{1}{c}{ Block } & $\bar{V}_{\mathrm{Pn}}$ & $\sum_{i=1}^{N} \sqrt{E_{i}}$ \\
\cline { 3 - 4 } & & $\mathrm{km} / \mathrm{s}$ & $\mathrm{J}^{1 / 2} \mathrm{yr}^{-1} \mathrm{~km}^{-2}$ \\
\hline \multirow{2}{*}{ Western region } & Northwest China & 8.14 & 18 \\
& Tibetan & 8.10 & 32 \\
\multirow{2}{*}{ Eastern region } & Yunnan-Burma & 8.00 & 36 \\
& North China & 7.99 & 4.6 \\
& Northeast Asia & 8.03 & 1.2 \\
& South China & 8.03 & 1.1 \\
\hline
\end{tabular}
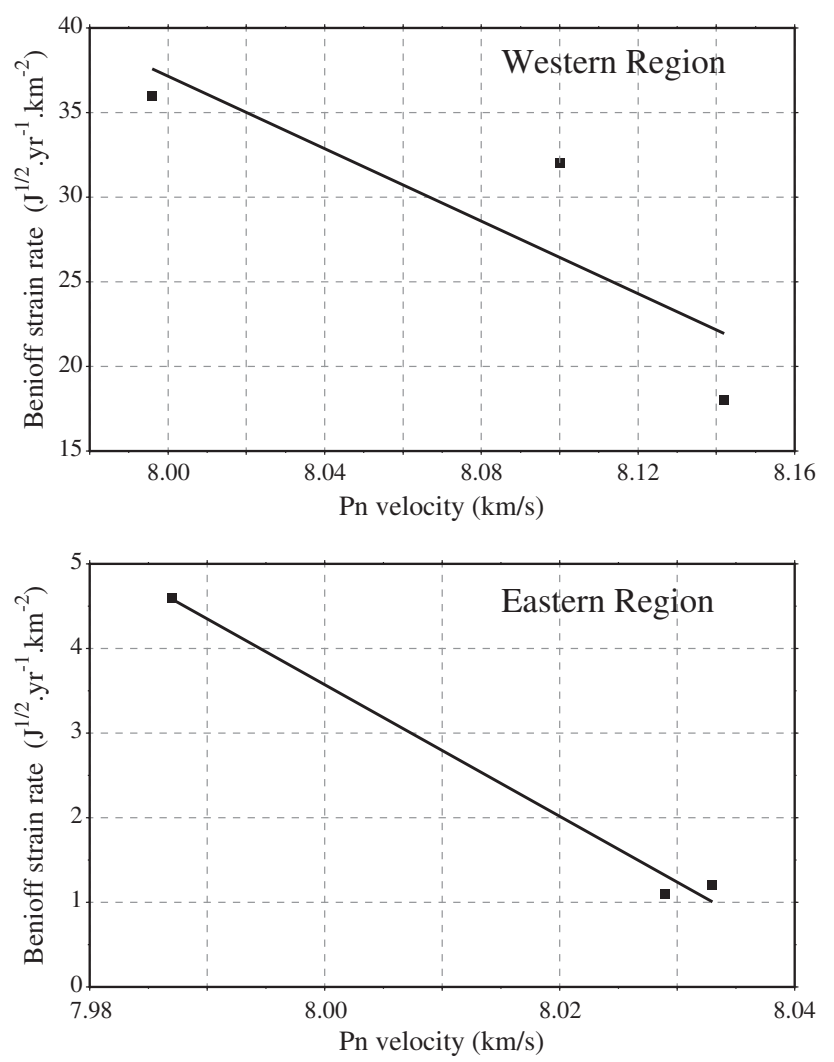

Figure 13. Benioff strain rate is shown as a function of average $P n$ velocity computed from the six major blocks in the (a) west and (b) east of the study area. Note the negative correlation between the strain rate and the $P n$ velocity, suggesting that the uppermost mantle velocity is closely related to the temperature-dependent lithospheric strength. observed $P n$ velocity and the calculated Benioff strain rate. However, if we divide the six blocks evenly into two groups: three western blocks and three eastern blocks, we found a clear negative correlation between the strain rate and $P n$ velocity for each group (Figure 13). This is consistent with the results of Zhang et al. [2003], which showed a strong correlation between seismicity and crustal and upper mantle velocity structure in China. As discussed above, the observed $P n$ velocity structure seems to be closely related to the stress field. The pressure difference associated with crustal thickness between the western and eastern parts of the study area is also expected to have a certain effect in leading to the observed $P n$ velocity structure. To see the relationship between strain rate and velocity, the Moho depth effect must be excluded. This might explain why the correlation can be seen only in regional scale, not the entire area.

\section{Summary and Conclusions}

[26] In this study, we measured the $P$-wave velocity in the uppermost mantle beneath East Asia with $P n$ arrival time. We further analyzed the potential relationship between the observed velocity structure and tectonic stress, as well as intraplate seismicity. We summarize the major features and findings as the following: (1) We integrated three sets of catalog data to compile a very large $P n$ data set, which has a total of 296,334 raypaths recorded by 1354 seismic stations from 27,777 earthquakes in East Asia. The inverted $P n$ velocity shows an average value of $8.03 \mathrm{~km} / \mathrm{s}$ and varies between $-0.42 \mathrm{~km} / \mathrm{s}$ and $0.41 \mathrm{~km} / \mathrm{s}$. The uppermost mantle velocity structure exhibits a clear east-west dichotomy. The western Pacific and eastern China show a distinctly lower $P n$ velocity than the western region. The boundary of the two regions is located roughly at $108^{\circ}$ east. We also found that seismically active regions tend to have lower $P n$ velocity than their surroundings. (2) East Asia is one of the most tectonically active regions on the Earth due to the strong interactions among the Indian, Eurasia, Pacific, and Philippine plates. The observed $P n$ velocity contrast between west and east may be either directly or indirectly related to the compressional and extensional tectonic backgrounds of the two regions, respectively. Quantitative difference in tectonic stress between the eastern and western regions is further shown by the orientation of the $P$ axis of 2548 earthquakes in the study region, which revealed a predominantly NS- and EW-oriented $P$ axes in the west and east, respectively. (3) Despite the very different tectonic settings between the west and east, there is a clear negative correlation between the $P n$ velocity and the Benioff strain rate in each region.

[27] Acknowledgments. We thank the China Earthquake Administration and the International Seismological Center for providing seismic data, and Dr. Thomas Hearn for providing the inversion code. We would also like to thank Professor Xuezhe Wen, Drs. Zhigang Shao and Langping Zhang for their comments and helps during the study, Dr. Thomas Hearn and an anonymous reviewer for providing constructive reviews, which significantly improved the quality of the manuscript. This work was supported by the Ministry of Science and Technology of China under contract 2011DFB20120-04 (S.W. and G.Z.) and the NSF grant EAR-063566 (F.N.).

\section{References}

Benioff, H. (1951), Earthquakes and rock creep (Part I: Creep Characteristics of Rocks and the Origin of aftershocks), Bull. Seism. Soc. Am. 41, 31-62.

Brace, W. F., and D. L. Kohlstedt (1980), Limits on lithostatic stress imposed by laboratory experiments, J. Geophys. Res. 85, 6248-6252. 


\section{WANG ET AL.: EAST ASIA PN TOMOGRAPHY}

Chen, W.-P., and P. Molnar (1983), Focal depths of intracontinental and intraplate earthquakes and their implications for the thermal and mechanical properties of the lithosphere, J. Geophys. Res. 88, 4183-4214.

Chen, Y., F. Niu, R. Liu, Z. Huang, H. Tkalcic, L. Sun, and W. Chan (2010), Crustal Structure beneath China from receiver function analysis, J. Geophys. Res., 115, B03307, doi:10.1029/2009JB006386.

Ding Z., R. Zeng, and F. Wu (1992), Pn velocity and Moho topography beneath the Tibetan plateau, Acta Seismologica Sinica 14, 592-599.

Dziewonski, A. M., T.-A. Chou, and J. H. Woodhouse, (1981), Determination of earthquake source parameters from waveform data for studies of global and regional seismicity, J. Geophys. Res. 86, 2825-2852.

Efron, B., and R. Tibshirani (1986), Bootstrap methods for standard errors, confidence intervals, and other measures of statistical accuracy, Stat. Sci. $1,54-75$.

Engdahl, E. R., R. van der Hilst, and R. Buland (1998), Global teleseismic earthquake relocation with improved travel times and procedures for depth determination, Bull. Seism. Soc. Am. 88, 722-743.

Gripp, A. E., and R. G. Gordon (2002), Young tracks of hotspots and current plate velocities, Geophys. J. Int. 150, 321-361.

Gutenberg, B., and F. Richter (1956), Earthquake Magnitude, Intensity, Energy and Acceleration (second paper), Bull. Seism. Soc. Am. 46, 105-145.

Hasegawa, A., D. Zhao, S. Hori, A. Yamamoto, and S. Horiuchi (1991), Deep structure of the northeastern Japan arc and its relationship to seismic and volcanic activity, Nature 352, 683-689.

Hearn, T. M. (1996), Anisotropic Pn tomography in the western United States, J. Geophys. Res. 101, 8,403-8,414.

Hearn, T. M., and J. F. Ni (1994), Pn velocities beneath continental collision zones: the Turkish-Iran Plateau, Geophys. J. Int. 117, 273-283.

Hearn, T. M., N. Beghoul, and M. Barazangi (1991), Tomography of the western United States from reginal arrival times, J. Geophys. Res. 96, $16,369-16,381$

Hearn, T. M., S. Wang, J. F. Ni, Z. Xu, Y. Yu, and X. Zhang, (2004), Uppermost mantle velocities beneath China and surrounding regions, J. Geophys. Res. 109, B11301, doi:10.1029/2003JB002874.

Lee, C.-T. A. (2003), Compositional variation of density and seismic velocities in natural peridotites at STP conditions: implications for seismic imaging of compositional heterogeneities in the upper mantle, J. Geophys. Res. 108, 2441.

Li, S., and W. D. Mooney (1998), Crustal structure of China from deep seismic sounding profiles, Tectonophysics 288, 105-113.

Liang, C. T., X. D. Song, and J. L. Huang (2004), Tomographic inversion of Pn travel-times in China, J. Geophys. Res., 109, B11304, doi:10.1029/ 2003JB002789.
Ma, Y., and H. Zhou (2007), Crustal thickness and Poisson's ratios in China by joint analysis of teleseismic receiver function and Rayleigh wave dispersion, Geophys. Res. Lett., 34, L12304, doi:10.1029/2007GL029848.

Molnar, P., and P. Tapponnier (1975), Cenozoic tectonics of Asia: Effects of a continental collision, Science 1989, 419-426.

Pan, S., and F. Niu (2011), Large contrasts in crustal structure and composition between the Ordos plateau and the NE Tibetan plateau from receiver function analysis, Earth Planet, Sci. Lett., 303, 291-298, doi:10.1016/j.eps1.2011.01.007.

Pei, S., Z. Xu, S. Wang, and T. M. Hearn (2002), Pn velociy tomography in Xinjiang, China and adjacent regions, Chin. J. Geophys. 45 (2), 218-225.

Pei, S. J., Y. Zhao, Z. Sun, S. Xu, H. Wang, C. A. Liu, M. N. Rowe, and X. Gao Toksöz (2007), Upper mantle seismic velocities and anisotropy in China determined through Pn and Sn tomography, J. Geophys. Res., 112, B05312,doi:10.1029/2006JB004409.

Sonder, L. J., and P. C. England (1989), Effect of temperature dependent rheology on large-scale continental extension, J. Geophys. Res. 94, 7603-7619.

Song, Z., G. Chen, and C. An (1993), Crustal and upper mantle 3D velocity structure beneath China and the surrounding seas, Sci. in Chin. Ser. D 23, $180-188$.

Sun, Y., F. Niu, H. Liu, Y. Chen, and J. Liu (2012), Crustal structure and deformation of the SE Tibetan plateau revealed by receiver function data: Seismic evidence for a lower crustal flow beneath the plateau, Earth Planet. Sci. Lett., 349-350, 186-197.

Thatcher, W. (1995), Continuum versus microplate models of active continental deformation. J. Geophys. Res. 100, 3,885-3,894

Wang, S., T. M. Hearn, Z. Xu, J. F. Ni, Y. Yu, and X. Zhang (2002), Velocity structure of uppermost mantle beneath China continent from Pn tomography. Sci. Chin. Ser. D 45, 144-150.

$\mathrm{Xu}, \mathrm{Y}$., F. Liu, and J. Liu (2000), Tomography study of the orogens and basins in northwest China. Sci. Chin. Ser. D 30, 113-122.

$\mathrm{Xu}, \mathrm{Z}$., S. Wang, and S. Pei (2003), Lateral variations in Pn velocity beneath the norteast margin of the Tibetan plateau. Acta Seismologica Sinica 25, 24-31.

Zhang, G., H. Ma, H. Wang, and L. Li (2004), Correlation between active tectonic blocks and strong earthquake activity in Mainland China. Sci. Chin Ser. D 34, 591-599.

Zhang, P., Q. Deng, G. Zhang, J. Ma, W. Gan, W. Min, F. Mao, and Q. Wang (2003), Active tectonic blocks and strong earthquakes in the continent of China, China. Sci. Chin. Ser. D 46, 13-24.

Zhao, D., A. Hasegawa, and S. Horiuchi (1992), Tomographic imaging of $\mathrm{P}$ and $\mathrm{S}$ wave velocity structure beneath northeastern Japan, $J$. Geophys. Res. 97, 19,909-19,928. 